\title{
Fetal cardiac interventions: clinical and experimental research
}

\author{
Shi-Min Yuan ${ }^{1}$, Gulimila Humuruola ${ }^{2}$ \\ ${ }^{1}$ The First Hospital of Putian, Teaching Hospital, Fujian Medical University, Putian, Fujian Province, China \\ ${ }^{2}$ People's Hospital of Jimunai, Altay Prefecture, Xinjiang Uygur Autonomous Region, China
}

Adv Interv Cardiol 2016; 12, 2 (44): 99-107

DOI: 10.5114/aic.2016.59359

\begin{abstract}
A bstract
Fetal cardiac interventions for congenital heart diseases may alleviate heart dysfunction, prevent them evolving into hypoplastic left heart syndrome, achieve biventricular outcome and improve fetal survival. Candidates for clinical fetal cardiac interventions are now restricted to cases of critical aortic valve stenosis with evolving hypoplastic left heart syndrome, pulmonary atresia with an intact ventricular septum and evolving hypoplastic right heart syndrome, and hypoplastic left heart syndrome with an intact or highly restrictive atrial septum as well as fetal heart block. The therapeutic options are advocated as prenatal aortic valvuloplasty, pulmonary valvuloplasty, creation of interatrial communication and fetal cardiac pacing. Experimental research on fetal cardiac intervention involves technical modifications of catheter-based cardiac clinical interventions and open fetal cardiac bypass that cannot be applied in human fetuses for the time being. Clinical fetal cardiac interventions are plausible for midgestation fetuses with the above-mentioned congenital heart defects. The technical success, biventricular outcome and fetal survival are continuously being improved in the conditions of the sophisticated multidisciplinary team, equipment, techniques and postnatal care. Experimental research is laying the foundations and may open new fields for catheter-based clinical techniques. In the present article, the clinical therapeutic options and experimental fetal cardiac interventions are described.
\end{abstract}

Key words: fetal cardiac interventions, congenital heart defects, prognosis.

\section{Introduction}

Fetuses with congenital heart defects (CHDs), such as hypoplastic left heart syndrome (HLHS), may develop irreversible pathological changes in the cardiovascular system and they may lose the opportunity for a radical surgical repair [1]. Intrauterine death or spontaneous abortion is possible in these fetuses due to postplacental hypoxia in the presence of complex CHDs [2]. The early relief of heart obstructions may promote ventricular and vascular growth and improve postnatal outcomes [3]. In the early years, postnatal intervention had to be adopted even with a prenatal diagnosis because of the unavailability of fetal echocardiography [4]. Nowadays, the advent of diagnostic tools, such as echocardiography, electrocardiography and magnetocardiography for fetal CHDs, has made prenatal diagnosis feasible [5]. At the end of the 1980s, four-chamber view echocardiography became an integral part of fetal cardiac evaluations [6], but in some instances it could not properly display the fetal anatomy with acceptable visualization [7, 8]. In the early 1990s, the introduction of color flow imaging allowed for a better understanding of the pathophysiology of fetal CHDs [9]. Subsequently, noninvasive medical imaging techniques gained popularity in the diagnosis of these defects [10]. Nowadays, the diagnosis of fetal CHDs is possible at midgestation during 18-24 gestational weeks [11] or even 12-14 gestational weeks [12]; however, echocardiographic evaluations of fetal CHDs during early (<20 weeks) or late ( $>34$ weeks) gestation can sometimes be problematic due to the poor quality of the medical imaging or maternal obesity [11].

The earliest reported human fetal cardiac therapy was in 1975 and involved the maternal-fetal transplacental administration of a $\beta$-blocker in the setting of fetal ventricular tachyarrhythmia [13]. The first open intrauterine cardiac procedure was performed a decade later in 1986 with the insertion of a pacemaker for complete heart block [14]. Successful fetal balloon valvuloplasty for aortic stenosis (AS) was first reported in 1989 [15].

Corresponding author:

Shi-Min Yuan MD, PhD, The First Hospital of Putian, Teaching Hospital, Fujian Medical University, 389 Longdejing St, Chengxiang District, 351100 Putian, Fujian Province, China, phone: +86 1801201 8138, e-mail: shi_min_yuan@yahoo.com

Received: 21.07.2015, accepted: 4.10.2015. 
Experimental studies on animal models that explore the pathophysiology and attempt to understand the nature, history and possible therapeutic outcomes of fetal CHDs provide valuable knowledge necessary for clinical practice [16]. In humans, fetal cardiac interventions are typically catheter-based interventional techniques, and open fetal cardiac interventions represent a challenging issue due to the limitation of fetal bypass technique [17]. The present article aims to present the therapeutic options of clinical and experimental fetal cardiac interventions.

\section{Clinical fetal cardiac intervention}

\section{Candidates}

Prenatally diagnosed CHDs, including critical AS (1.6\%), pulmonary atresia with intact ventricular septum (1.9\%), and severe pulmonary valve stenosis (1.5\%), may warrant intrauterine interventions [18]. Dietzel [19] confirmed that those with critical AS with evolving HLHS, pulmonary atresia with an intact ventricular septum and evolving hypoplastic right heart syndrome, and HLHS with an intact or highly restrictive atrial septum are good candidates for fetal cardiac interventions. Candidates for minimally invasive techniques (percutaneous access, only one cardiac puncture and placental avoidance) who are free of complications (fetal bradycardia, effusions and thrombus) are also ideal targets for fetal interventional techniques [20].

\section{Intrauterine balloon aortic valvuloplasty}

Fetal left ventricular outflow obstruction with significant reduced flow through the left heart system can progress into HLHS [21]. This phenomenon has been verified by experimental studies on left ventricular inflow or outflow obstruction in midgestational fetal lambs [22]. Clinical observations showed that all 17 of 43 fetuses that progressed into HLHS had a retrograde flow in the transverse aortic arch. In addition, 88\% had a left-to-right flow across the foramen ovale, $91 \%$ had a monophasic mitral inflow, and $94 \%$ had significant left ventricular dysfunction. However, all six fetuses with postnatal biventricular circulation had an antegrade flow in the transverse aortic arch, a biphasic mitral inflow and normal left ventricular function [23].

The entry criteria for prenatal critical AS intervention are severe AS or atresia with severe left ventricular dysfunction along with a left ventricular length of $\geq 2$ SDs below the mean for gestational age at diagnosis. The timing of the intervention is critical because of the rapid progression within weeks to left ventricular growth failure due to either the development of the phenotype of HLHS or substantial damage of the left ventricle (LV) that is unsuitable to support the systemic circulation [24]. Fetal AS associated with a dilated LV, and a mitral valve with a $Z$ score of $\geq-2.4$ is considered to be suitable for fetal intervention [25]. Mitral valve disease with mitral stenosis and regurgitation often coexists with AS. If the aortic valve has a sufficient orifice at an early stage before the left ventricle is severely damaged, it is possible to improve the mitral valve and LV growth speeds so that the child may have postnatal biventricular circulation [26].

Fetal cardiac intervention for severe AS was first reported by Maxwell et al. [15] in 1991 when they performed percutaneous balloon aortic valvuloplasty on two fetuses. The procedural frustration in a 28 -week-old fetus was attributed to the failure of the guidewire to pass through the aortic valve, but aortic valve intervention was successful in a 33-week-old fetus. In the developed countries, fetal CHDs can be diagnosed by echocardiography at midgestation (16-24 gestational weeks), and the fetal cardiac intervention can be advanced to 20-26 gestational weeks, which is known as the "window stage" of fetal cardiac intervention. Prior to 2000, fetal cardiac intervention was usually carried out at 27-33 gestational weeks [27], whereas the intervention has been performed at 21-29 gestational weeks since 2004 [24]. Arzt et al. [28] performed 24 aortic valvuloplasties on 23 fetuses with a critical AS at gestational week 26 (range: 21-32), and they achieved a technical success rate of $66.7 \%$ and a biventricular repair rate of $66.7 \%$. Recently, Goldstein et al. [29] introduced the standard Primewire PRESTIGE coronary guidewire (Volcano Corp., San Diego, CA, USA) into fetal aortic valvuloplasty. This can be smoothly inserted into the LV across the severely stenotic aortic valve, leading to an immediate aortic pressure drop after the intervention in their cases. Selamet et al. [30] also determined that there was an improvement in the left heart physiology in most cases after performing the intervention using this guidewire. They noted an increased biphasic mitral inflow and a greater bidirectional flow across the patent foramen ovale as well as a higher antegrade flow in the transverse arch. Furthermore, mitral regurgitation was alleviated when this device was used in the valvuloplasty procedure. The procedure of fetal aortic balloon valvuloplasty is illustrated in Figure 1.

Fetuses with critical semilunar valvular obstruction may benefit from timely cardiac interventions aiming at promoting ventricular growth and function, preventing intrauterine death and increasing survival [27]. In the early years, fetal cardiac interventions showed poor outcomes, probably related to poor ultrasonographic imaging, limitations of equipment availability and poor fetal conditions [31]. Kohl et al. [27] stated that poor outcomes were attributed to the selection of severe cases and technical problems during the procedure. Currently, the technical success of fetal cardiac interventions has been associated with significantly increased postnatal biventricular outcomes, evading subsequent postnatal palliation or cardiac transplant procedures [32]. Therefore, improved patient selection and technical innovations when 
interventional methods are applied are emphasized. The success rate of intrauterine aortic valvuloplasty for AS depends on the patient's cardiac structural pathology as well as the sophistication of the devices and equipment used in the procedure and the experience of the operating team. In their study, Tworetzky et al. [24] had a success rate of $81 \%$ of fetuses at 21-26 gestational weeks, and Gül et al. [33] determined that the mortality and morbidity of fetal AS primarily depend on technical errors. However, they also noted that the hemodynamic effects of AS along with the adaptation, development and function of the LV during fetal life play a role. Multiple single ventricle and biventricular management strategies can be available for patients with critical left ventricular outflow tract obstruction, but all carry a significant risk of death and require further interventions in the future [34]. In patients with development of borderline left ventricular structures, it is difficult to make a decision on which of the single and biventricular repair options is optimal, but potential for growth of the aorta and left ventricle should be carefully evaluated before a biventricular repair procedure is applied [35]. The long-term benefits and quality of life of patients relating to these choices of treatments remain unknown [34]. In cases with better growth of the aortic valve without the possibility of performing biventricular correction, the patient may develop heart functional impairment easily and may lose the chance of further intervention. McElhinney et al. [36] presented the largest study population and provided a very useful guideline for the management of a fetus with HLHS. Comparisons of postnatal biventricular with univentricular outcome after intrauterine aortic valvuloplasty revealed that $Z$ scores of the aortic annulus, ascending aorta and left ventricle long-axis dimensions, left ventricle sphericity and high left ventricle pressure were significant predictors of the postnatal outcome. Fetuses with a biventricular outcome had a significantly higher left ventricle length $Z$-score and a significantly higher left ventricle/right ventricle ratio. The biventricular group newborns had only aortic valve balloon dilation in the first postnatal week, without requiring further surgery. Their adequate left ventricular function after intervention rendered them free of prostaglandin treatment [28]. Patients who were initially managed with a univentricular palliative strategy and converted to a biventricular circulation after initial univentricular palliation carried a much higher incidence of morbidity, worse survival and more cardiac deaths than the patients with initial biventricular repair [25].

\section{Intrauterine pulmonary valvuloplasty}

Pulmonary atresia (PA) with intact ventricular septum (IVS) is a rare CHD characterized by fibromuscular atresia of the right ventricular outflow tract, severe right ventricular and TV hypoplasia and coronary anomaly that

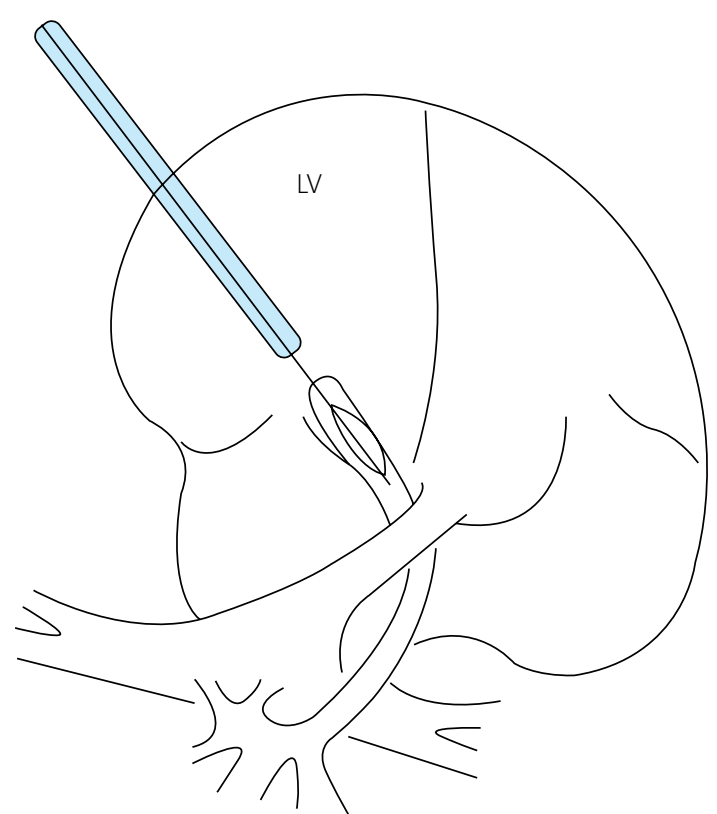

Figure 1. Schematic diagram of fetal aortic balloon valvuloplasty

LV-left ventricle.

can be diagnosed prenatally via fetal echocardiography and can be managed during midgestation [37]. Fetuses with critical pulmonary stenosis or membranous PA have also been considered for prenatal intervention. Hypoplasia of the tricuspid valve (TV) annulus may be cured by pulmonary valve intervention due to subsequent sufficient right heart growth [10]. Fetuses with minute TV, diminutive right ventricles and large coronary fistulae are not suitable candidates for fetal intervention because it can cause non-biventricular circulation [26]. In addition, fetuses with significant myocardiopathy due to chronic right ventricular hypertrophy may not be good candidates for valvulotomies since they have no ventricular reserve to respond positively to the valvuloplasty. However, the transplacental administration of terbutaline may help improve heart function in these cases [12]. Fetal cardiac interventions for PA/IVS were often associated with premature delivery, fetal demise, or neonatal death [38]. Daubeney et al. [39] noted that with advancing gestation, a steady increase of the right ventricle-to-pulmonary artery gradient was seen in their patients and that there was a high rate of pregnancy termination (61\%) and intrauterine death (5\%) if this was left untreated. Intrauterine pulmonary valvuloplasty for PA/IVS facilitated RV antegrade blood flow, allowing right heart growth and improvement of postnatal survival with a biventricular circulation [37]. Fetal pulmonary balloon valvuloplasty is technically feasible in midgestation. However, since intrauterine pulmonary valvuloplasty for PA/IVS is so challenging, there are few reports that have described this procedure. If the optimal fetal position could not be achieved or imaging was inadequate, a limited maternal 
laparotomy without uterine exteriorization or incision is performed [37, 40]. Prenatal intervention for fetal PA/IVS was performed by Tworetzky et al. [37] for membranous $\mathrm{PA}$, an intact or highly restrictive ventricular septal defect and right heart hypoplasia with a TV annulus $Z$ score of $<-2$. Compared with the fetuses with PA/IVS with postnatal univentricular circulation as a result of lack of prenatal intervention, the TV annulus, right ventricular length and pulmonary valve annulus grew significantly more from the midgestational to the late gestational periods in the six fetuses who underwent successful interventions. This procedure is performed under either local or general anesthesia. Under ultrasound guidance, the needle is introduced into the amniotic sac and a 0.014inch, floppy-tipped guidewire is advanced through the needle to cross the pulmonary valve. A balloon catheter is then inserted and inflated to dilate the stenotic valve. After access to the right ventricular outflow tract is achieved through direct puncture via a 19-gauge cannula by way of a subcostal or an intercostal approach, the cannula tip is directed into the right ventricular outflow tract and the atretic pulmonary valve is intervened by coronary angioplasty balloon inflations [40]. Gómez Montes et al. [41] performed pulmonary valvuloplasty on four fetuses with PA/IVS at a mean gestational age of 25 weeks; they achieved $100 \%$ technical success and observed postinterventional developmental and hemodynamic improvements. Successful fetal pulmonary valvuloplasties with critical pulmonary valve stenosis at midgestation have been sporadically reported, thus illustrating the immediate hemodynamic improvement and postinterventional event-free survival [42-44]. In one of these studies, Polat et al. [43] applied a coronary balloon catheter in the procedure. It was first directed into the left pulmonary artery and then withdrawn through the perforated valve with successive inflations. Roman et al. [45] determined that midgestational fetal TV $Z$ scores of $>-3$ and good TV growth were important factors leading to postnatal biventricular repair. Of the 27 live-born babies who underwent intrauterine pulmonary valvuloplasty for PA/IVS, eight had non-biventricular outcomes and 19 had biventricular circulation with a biventricular repair rate of $70.4 \%$. They also confirmed the sensitivity of the four-criteria scoring system (a TV/ mitral valve ratio of $<0.7$, a right ventricle/LV length ratio of $<0.6$, a TV inflow duration of $<31.5 \%$ of the cardiac cycle length, and the presence of right ventricular sinusoids) when predicting postnatal non-biventricular outcomes.

\section{Prenatal intervention on the atrial septum}

Fetuses with a restrictive interatrial septum should be scheduled for early intervention. A fetal restrictive atrial septum has been defined as a small or absent interatrial shunt on two-dimensional echocardiographic imaging and has a mean pulmonary vein forward/reverse time-velocity integral ratio of $\leq 5$ [46]. In a fetus with critical left heart obstruction, a threshold ratio of $\leq 3$ optimizes the specificity for predicting an emergency atrial septostomy [46].

The HLHS is detectable by echocardiography via a four-chamber view in the fetuses at 18-22 gestational weeks. With left heart obstruction, the presence of interatrial communication is very important so that oxygenated blood can be distributed throughout the body and pulmonary congestion can be prevented [47]. By accessing the fetal heart, the communication is created by directing the needle across the atrial septum. Next, a guidewire and a small balloon are moved into the left atrium, and the limited atrial communication is enlarged by inflating the balloon [48]. In 2004, Marshall et al. [49] presented their initial experiences with intrauterine atrial septoplasty in which they achieved technical success in six of seven fetuses with HLHS and an intact atrial septum (IAS). However, one fetus with a large right hemothorax and small hemopericardium died during the early postinterventional period. Later, Marshall et al. [50] updated their findings in a larger series of 21 fetuses with HLHS at 24-34 gestational weeks. There were 19 technical successes and two fetal deaths. In spite of the atrial communications of at least $3 \mathrm{~mm}$ in diameter to allow for heart growth, the postnatal mortality rate was as high as 58\%.

Fetal atrial septal stent placement is an alternative option for keeping the septectomy open [51, 52]. In spite of fetal complications in those studies, for example stent placement failure, stent stenosis and even fetal demise, stent deployment may decompress the fetal left atrium. Quintero et al. [53] performed atrial septotomy using Neodymium-YAG laser photofulguration for a fetus with HLHS/IAS at 30-week gestation. The interatrial communication created by photofulguration was identified by Doppler echocardiography.

Pulmonary stenosis may be spontaneously relieved with the progression of intrauterine right heart growth, and the effect of fetal pulmonary valvuloplasty on the pulmonary circulation is not as conspicuous as that of fetal aortic valvuloplasty on the systemic circulation [18]. As a result, fewer prenatal pulmonary valvuloplasties have been reported compared to prenatal aortic valvuloplasties [3]. The initial technical success and biventricular repair rates were low, as shown by the high mortality of the primary interventions for valvuloplasty and atrial septostomy. Technical success, biventricular outcome and fetal survival are steadily improved in the context of a well-trained multidisciplinary team, sophisticated equipment and techniques, and better postnatal care [28]. Despite the progress made in this field, fetal cardiac interventions still remain controversial in terms of entry criteria for candidate selections and postinterventional outcomes (Table I). Lee and Comstock [54] accentuat- 
ed the importance of a standardized diagnostic training team for prenatal diagnosis of CHDs. Tworetzky et al. [55] stated that a multidisciplinary team with well-established practice guidelines may overcome these limitations and guarantee technical success. In brief, technical error and poor candidate selection are regarded as the two major risk factors that constrain the development of fetal cardiac interventions in clinical practice.

Boston Children's Hospital has done good work in fetal cardiac interventions in terms of patient population, mature devices, advanced multidisciplinary teams and superior fetal outcomes (Table II).

\section{Experimental research}

In order to improve the technical success and survival rates, modifications of the catheter-based techniques have been increasingly attempted in experimen- tal animals. Emery et al. [56] tested a computer-assisted navigation (CANav) system in a fetal sheep model in which the duration of fetal cardiac intervention could be shortened by tracking the position and orientation of the fetus via ultrasound guidance. Schmidt et al. [57] deployed coronary stents via a percutaneous, ultrasound guided transpulmonary or transhepatic approach in the atrial septum primum in 10 normal fetal sheep and achieved a technical success rate of $80 \%$. They also found that transpulmonary implantation without a laparotomy or uterine exteriorization was only possible when the fetuses were in a prone position and not a supine position. Furthermore, their study revealed that after the intervention, five fetuses suffered complications, with three cases of pleural effusion, one of stent dislodgement and another with partial stent occlusion by endocardial cells.

Table I. A comparison between three indications for fetal cardiac intervention

\begin{tabular}{|c|c|c|c|}
\hline Indication & AS & PS & PA/IAS \\
\hline Study population & $23-70[28,34]$ & $4[39]$ & $7-21[47,48]$ \\
\hline Entry criteria & $\begin{array}{l}\text { Critical AS } \\
\text { Evolving HLHS } \\
\text { LV long-axis Z score } \geq-2\end{array}$ & $\begin{array}{l}\text { Membranous pulmonary atresia } \\
\text { An intact or highly restrictive } \\
\text { ventricular septum } \\
\text { Right heart hypoplasia, with a TV } \\
\text { annulus Z score }<-2\end{array}$ & $\begin{array}{l}\text { Critical pulmonary stenosis or } \\
\text { membranous pulmonary atresia } \\
\text { Hypoplasia of the tricuspid valve } \\
\text { annulus } \\
\text { TV } Z \text { score }<-2\end{array}$ \\
\hline Fetal age (gestational week) & $21-29[24]$ & $21-32[38]$ & $24-34[48]$ \\
\hline Technique & $\begin{array}{l}\text { Maternal anesthesia and fetal } \\
\text { analgesia } \\
\text { A 15- or 20-cm, 18-gauge needle } \\
\text { Ultrasound guidance } \\
\text { Fetal subcostal approach } \\
\text { accessing LV near the apex } \\
\text { 3-5 dilations (6-15 bar) with } \\
\text { a standard coronary monorail } \\
\text { balloon catheter }\end{array}$ & $\begin{array}{l}\text { Maternal anesthesia and fetal } \\
\text { analgesia } \\
\text { A 19-gauge ultra-thin-walled } \\
\text { cannula } \\
\text { Fetal subcostal approach } \\
\text { accessing RVOT } \\
\text { A 0.014-inch, floppy-tipped } \\
\text { guidewire } \\
\text { Inflations with a coronary } \\
\text { angioplasty balloon }\end{array}$ & $\begin{array}{l}\text { 1) Fetal septotomy with coronary } \\
\text { angioplasty balloon [47]: } \\
\text { - Maternal and fetal anesthesia; } \\
\text { an 18- or 19-gauge introducer } \\
\text { cannula } \\
\text { - Fetal subcostal approach to the } \\
\text { right atrial epicardial surface } \\
\text { - Diamond-shaped obturators; } \\
\text { a 22-gauge Chiba needle for } \\
\text { atrial septum puncture } \\
\text { - Dilation with a 3-mm coronary } \\
\text { angioplasty balloon or } \\
\text { 2) Fetal atrial septal stent } \\
\text { deployment [49, 50] or } \\
\text { 3) Atrial septotomy using } \\
\text { neodymium-YAG laser } \\
\text { photofulguration [51] }\end{array}$ \\
\hline Technical success (\%) & $66.7[28]$ & $100[39]$ & $85.7-90.5[47,48]$ \\
\hline Biventricular repair (\%) & $26.1-66.7[23,28]$ & $70.4[43]$ & - \\
\hline Postinterventional benefit & $\begin{array}{l}\text { An immediate aortic pressure drop } \\
\text { Left heart physiological } \\
\text { improvement } \\
\text { Biphasic mitral flow increment } \\
\text { Attenuated mitral regurgitation }\end{array}$ & $\begin{array}{l}\text { Developmental and hemodynamic } \\
\text { improvements }\end{array}$ & $\begin{array}{l}\text { Higher oxygen saturation } \\
\text { Growth of TV annulus, RV length } \\
\text { and PV annulus }\end{array}$ \\
\hline Pertinent predictors of fetus & $\begin{array}{l}Z \text { scores of the aortic annulus, } \\
\text { ascending aorta and LV long-axis } \\
\text { - dimensions } \\
\text { - LV sphericity } \\
\text { - high LV pressure }\end{array}$ & $\begin{array}{l}\text { TV/mitral valve ratio of }<0.7 \\
\text { RV/LV length ratio }<0.6 \\
\text { TV inflow duration }<31.5 \% \text { of the } \\
\text { cardiac cycle length } \\
\text { Presence of RV sinusoids }\end{array}$ & Antegrade flow through RV \\
\hline
\end{tabular}




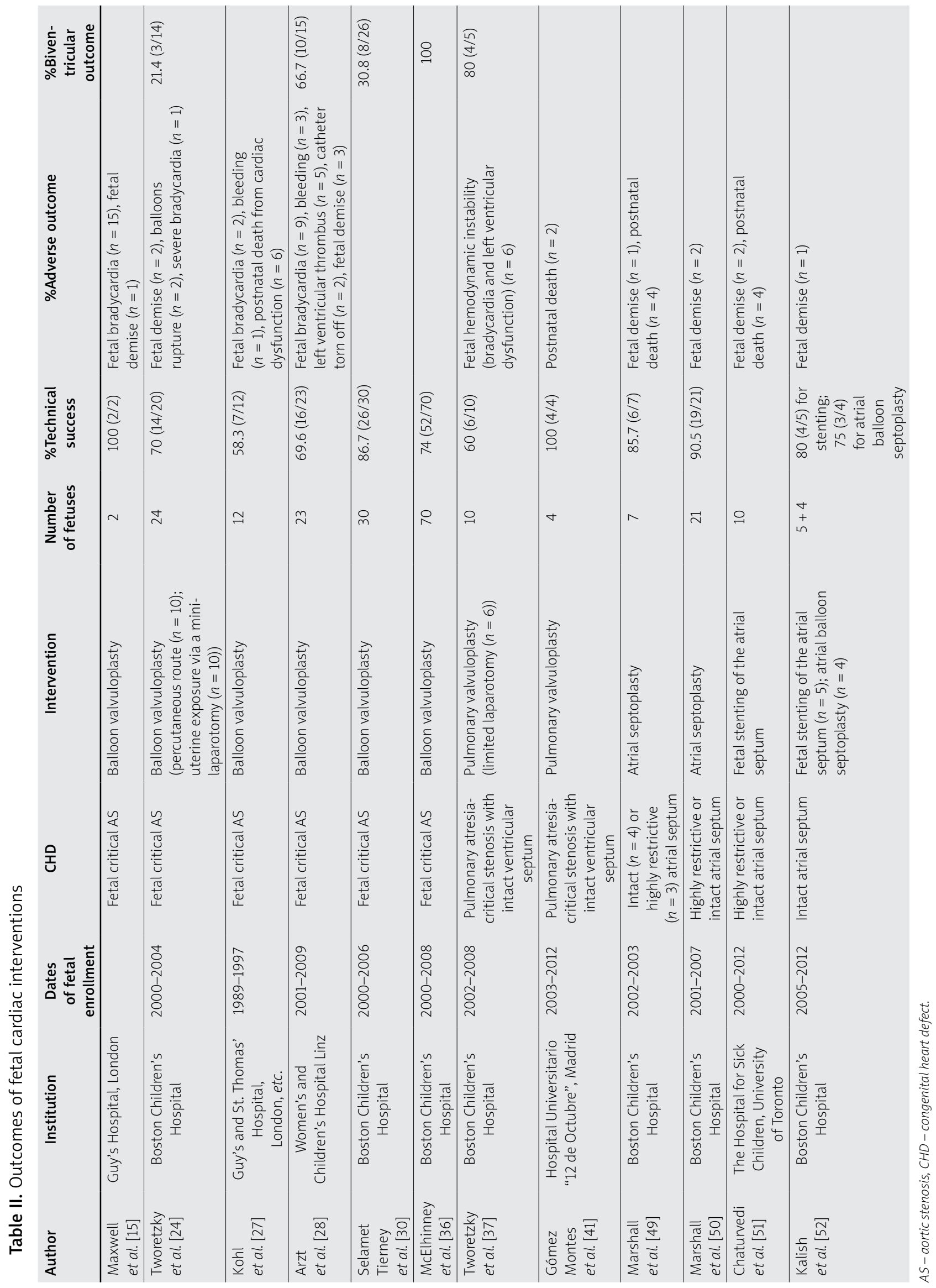


Experimental studies on open fetal cardiac surgery began in the 1980s with an aim of studying the physiological and pathological mechanisms of fetal cardiac bypass [58]. In cases in which cardiothoracic lesions, such as pulmonary stenosis, AS and diaphragmatic hernias, were indicated, Eghtesady et al. [59] determined that the fetuses could benefit from fetal open heart surgery because it provided improved postoperative outcomes. In their study, pregnant ewes at 100-109-day pregnancy were bypassed for a total of $60 \mathrm{~min}$. Decreases in uterine blood flow were observed, but these did not influence the maternal hemodynamics or arterial blood gases. However, worsening fetal arterial blood gases were noted. Ikai et al. [60] noted that in fetal lamb models with AS or pulmonary stenosis, a significant decrease in uteroplacental flows was associated with fetal cardiac surgery, including a fetal sternotomy, cannulation and cardiopulmonary bypass. Eghtesady et al. [59] tested the efficacy of different anesthetic approaches in nine baboon fetuses with an average gestation of 146 days. Cardiac bypass was successful in all of the fetuses in the isoflurane group but failed in two animals in the fentanyl and midazolam groups due to sustained elevations of the maternal uterine tone. As a result, all the maternal baboons survived. Five of six fetuses in the isoflurane group survived for $1 \mathrm{~h}$; however, they developed postbypass functional deteriorations of the placentas.

It has been proposed that fetal cardiac bypass causes placental dysfunction associated with deranged endothelial regulation of the placental vascular tone. Non-physiological flow pattern and increased shear stress are important regulators of the placental vascular tone and thus contribute to placental dysfunction. Endothelin receptor blockade may reduce postbypass placental dysfunction [61]. To date, no successful fetal cardiac bypass has been reported in humans. In short, fetal cardiac bypass is difficult to perform and it may bring about placental dysfunction [62]. Attempts to make substantial improvements of fetal cardiac bypass outcomes are underway with regard to technical modifications and candidate selection. In spite of the reproducibility of experimental fetal cardiac bypass, fetal hypoxia and demise subsequent to cytokine-mediated injury and placental dysfunction following bypass significantly impede the technical application in human fetuses.

\section{Conclusions}

Clinical fetal cardiac interventions for CHDs are feasible during midgestation for improving fetal cardiac function, minimizing fetal loss and enhancing postnatal biventricular repair and neonatal survival. A well-trained multidisciplinary team with sophisticated equipment is required for improving the technical success rate and post-interventional outcomes. Clinical and experimental research on the understanding of the natural history and sufficient evaluation of fetal heart disease are adjunctive ways for candidate selection and the improvement of fetal cardiac intervention outcomes. Experimental research of fetal cardiac interventions is laying the foundations and opening new fields for minimally invasive clinical techniques. Future directions of fetal cardiac interventions are a combination of nonsurgical cardiac therapy with minimally invasive surgical techniques, such as robot-guided fetal cardiac intervention, fetoscopic fetal cardiac surgery and open cardiac surgery. More and more advantageous techniques and better outcomes are anticipated.

\section{Conflict of interest}

The authors declare no conflict of interest.

\section{References}

1. Donofrio MT, Moon-Grady AJ, Hornberger LK, et al. Diagnosis and treatment of fetal cardiac disease: a scientific statement from the American Heart Association. Circulation 2014; 129: 2183-242.

2. Hutter D, Kingdom J, Jaeggi E. Causes and mechanisms of intrauterine hypoxia and its impact on the fetal cardiovascular system: a review. Int J Pediatr 2010; 2010: 401323.

3. Matsui $H$, Gardiner H. Fetal intervention for cardiac disease: the cutting edge of perinatal care. Semin Fetal Neonatal Med 2007; 12: 482-9.

4. Huhta JC, Carpenter RJ Jr, Moise KJ Jr, et al. Prenatal diagnosis and postnatal management of critical aortic stenosis. Circulation 1987; 75: 573-6.

5. Montaña E, Khoury MJ, Cragan JD, et al. Trends and outcomes after prenatal diagnosis of congenital cardiac malformations by fetal echocardiography in a well defined birth population, Atlanta, Georgia, 1990-1994. J Am Coll Cardiol 1996; 28: 1805-9.

6. Allan L. Prenatal diagnosis of structural cardiac defects. Am J Med Genet Part C Semin Med Genet 2007; 145C: 73-6.

7. Achiron R, Glaser J, Gelernter I, et al. Extended fetal echocardiographic examination for detecting cardiac malformations in low risk pregnancies. BMJ 1992; 304: 671-4.

8. Xu Y, Hu YL, Ru T, et al. Importance of "Guidelines for performing fetal cardiac scan" in prenatal screening for fetal congenital heart disease. Zhonghua Fu Chan Ke Za Zhi 2009; 44: 103-7.

9. Lee K, Khoshnood B, Chen L, et al. Infant mortality from congenital malformations in the United States, 1970-1997. Obstet Gynecol 2001; 98: 620-7.

10. Van Aerschot I, Rosenblatt J, Boudjemline Y. Fetal cardiac interventions: myths and facts. Arch Cardiovasc Dis 2012; 105: 366-72.

11. Allan LD, Chita SK, Sharland GK, et al. The accuracy of fetal echocardiography in the diagnosis of congenital heart disease. Int J Cardiol 1989; 25: 279-88.

12. Pavlovic M, Acharya G, Huhta JC. Controversies of fetal cardiac intervention. Early Hum Dev 2008; 84: 149-53.

13. Eibschitz I, Abinader EG, Klein A, et al. Intrauterine diagnosis and control of fetal ventricular arrhythmia during labor. Am J Obstet Gynecol 1975; 122: 597-600.

14. Carpenter RJ Jr, Strasburger JF, Garson A Jr, et al. Fetal ventricular pacing for hydrops secondary to complete atrioventricular block. J Am Coll Cardiol 1986; 8: 1434-6. 
15. Maxwell D, Allan L, Tynan MJ. Balloon dilatation of the aortic valve in the fetus: a report of two cases. Br Heart J 1991; 65: 256-8.

16. The Fetal Treatment Center. Fetal treatment research. http://fetus.ucsfmedicalcenter.org/our_team/research.asp. Accessed on April 5, 2014.

17. McElhinney DB, Tworetzky W, Lock JE. Current status of fetal cardiac intervention. Circulation 2010; 121: 1256-63.

18. Simpson JM. Fetal cardiac interventions: worth it? Heart 2009; 95: $1653-5$.

19. Dietzel B. Helping families access fetal cardiac intervention to interrupt evolving HLHS and HRHS. Congenit Cardiol Today 2011; 9: 14-5.

20. Bacha $E$. The impact of fetal cardiac intervention on neonatal cardiac surgery. http://av.conferencearchives.com/pdfs/100502/ 09.08.pdf. Accessed on March 10, 2015.

21. Danford DA, Cronican P. Hypoplastic left heart syndrome: progression of left ventricular dilation and dysfunction to left ventricular hypoplasia in utero. Am Heart J 1992; 123: 1712-3.

22. Fishman NH, Hof RB, Rudolph AM, et al. Models of congenital heart disease in fetal lambs. Circulation 1978; 58: 354-64.

23. Mäkikallio K, McElhinney DB, Levine JC, et al. Fetal aortic valve stenosis and the evolution of hypoplastic left heart syndrome: patient selection for fetal intervention. Circulation 2006; 113 : 1401-5.

24. Tworetzky W, Wilkins-Haug L, Jennings RW, et al. Balloon dilation of severe aortic stenosis in the fetus: potential for prevention of hypoplastic left heart syndrome: candidate selection, technique, and results of successful intervention. Circulation 2004; 110: 2125-31.

25. Freud LR, McElhinney DB, Marshall AC, et al. Fetal aortic valvuloplasty for evolving hypoplastic left heart syndrome: postnatal outcomes of the first 100 patients. Circulation 2014; 130: 638-45.

26. Gardiner HM. The case for fetal cardiac intervention. Heart 2009; 95: 1648-52.

27. Kohl T, Sharland G, Allan LD, et al. World experience of percutaneous ultrasound-guided balloon valvuloplasty in human fetuses with severe aortic valve obstruction. Am J Cardiol 2000; 85: $1230-3$.

28. Arzt W, Wertaschnigg D, Veit I, et al. Intrauterine aortic valvuloplasty in fetuses with critical aortic stenosis: experience and results of 24 procedures. Ultrasound Obstet Gynecol 2011; 37 : 689-95.

29. Goldstein BH, Fifer CG, Armstrong AK, et al. Use of a pressure guidewire in fetal cardiac intervention for critical aortic stenosis. Pediatrics 2011; 128: e716-9.

30. Selamet Tierney ES, Wald RM, McElhinney DB, et al. Changes in left heart hemodynamics after technically successful in-utero aortic valvuloplasty. Ultrasound Obstet Gynecol 2007; 30: 715-20.

31. Qureshi SA. Fetal interventions in congenital heart disease. http://www.sha-conferences.com/files/presentation2011/ 090005.pdf. Accessed on March 10, 2015.

32. Emery SP, Kreutzer J, McCaffrey FM, et al. The learning curve for a fetal cardiac intervention team. Minim Invasive Surg 2010; 2010: 674185

33. Gül A, Saygılı A, Kavuncuoğlu S, et al. Balloon valvuloplasty for critical aortic stenosis in a fetus: a case report. Turk Kardiyol Dern Ars 2013; 41: 161-5.

34. Alsoufi B, Karamlou T, McCrindle BW, et al. Management options in neonates and infants with critical left ventricular outflow tract obstruction. Eur J Cardiothorac Surg 2007; 31: 1013-21.
35. Brown SC, Boshoff D, Eyskens B, et al. Hybrid approach as bridge to biventricular repair in a neonate with critical aortic stenosis and borderline left ventricle. Eur J Cardiothorac Surg 2009; 35: 1080-2.

36. McElhinney DB, Marshall AC, Wilkins-Haug LE, et al. Predictors of technical success and postnatal biventricular outcome after in utero aortic valvuloplasty for aortic stenosis with evolving hypoplastic left heart syndrome. Circulation 2009; 120: 1482-90.

37. Tworetzky W, McElhinney DB, Marx GR, et al. In utero valvuloplasty for pulmonary atresia with hypoplastic right ventricle: techniques and outcomes. Pediatrics 2009; 124: e510-8.

38. Kohl T. Foetal cardiac interventions: overview and perspectives in 2012. Eur J Cardiothorac Surg 2012; 42: 14-6.

39. Daubeney PE, Sharland GK, Cook AC, et al. Pulmonary atresia with intact ventricular septum: impact of fetal echocardiography on incidence at birth and postnatal outcome. UK and Eire Collaborative Study of Pulmonary Atresia with Intact Ventricular Septum. Circulation 1998; 98: 562-6.

40. National Institute for Health and Clinical Excellence. Percutaneous fetal balloon valvuloplasty for pulmonary atresia with intact ventricular septum. www.nice.org.uk/ip323overview. Accessed on March 10, 2015.

41. Gómez Montes E, Herraiz I, Mendoza A, et al. Fetal intervention in right outflow tract obstructive disease: selection of candidates and results. Cardiol Res Pract 2012; 2012: 592403.

42. Galindo A, Gutiérrez-Larraya F, Velasco JM, et al. Pulmonary balloon valvuloplasty in a fetus with critical pulmonary stenosis/ atresia with intact ventricular septum and heart failure. Fetal Diagn Ther 2006; 21: 100-4.

43. Polat TB, Danısman N. Pulmonary valvulotomy in a fetus with pulmonary atresia with intact ventricular septum: first experience in Turkey. Images Paediatr Cardiol 2012; 14: 6-11.

44. Oylumlu M, Aykent K, Soydinc HE, et al. Pulmonary balloon valvuloplasty during pregnancy. Case Rep Cardiol 2012; 2012: 353168.

45. Roman KS, Fouron JC, Nii M, et al. Determinants of outcome in fetal pulmonary valve stenosis or atresia with intact ventricular septum. Am J Cardiol 2007; 99: 699-703.

46. Divanović A, Hor K, Cnota J, et al. Prediction and perinatal management of severely restrictive atrial septum in fetuses with critical left heart obstruction: clinical experience using pulmonary venous Doppler analysis. J Thorac Cardiovasc Surg 2011; 141: 988-94.

47. Cester M, Nanhorngue K, Pascoli I, et al. Hypoplastic left heart syndrome with intact atrial septum: case report. J Prenat Med 2007; 1: 32-4.

48. Balloon atrial septostomy for HLHS. http://women.texaschildrens.org/Our-Services/Fetal-Center/Balloon-Atrial-Septostomy-for-H LHS/. Accessed on March 10, 2015.

49. Marshall AC, van der Velde ME, Tworetzky W, et al. Creation of an atrial septal defect in utero for fetuses with hypoplastic left heart syndrome and intact or highly restrictive atrial septum. Circulation 2004; 110: 253-8.

50. Marshall AC, Levine J, Morash D, et al. Results of in utero atrial septoplasty in fetuses with hypoplastic left heart syndrome. Prenat Diagn 2008; 28: 1023-8.

51. Chaturvedi RR, Ryan G, Seed M, et al. Fetal stenting of the atrial septum: technique and initial results in cardiac lesions with left atrial hypertension. Int J Cardiol 2013; 168: 2029-36.

52. Kalish BT, Tworetzky W, Benson CB, et al. Technical challenges of atrial septal stent placement in fetuses with hypoplastic left 
heart syndrome and intact atrial septum. Catheter Cardiovasc Interv 2014; 84: 77-85.

53. Quintero RA, Huhta J, Suh E, et al. In utero cardiac fetal surgery: laser atrial septotomy in the treatment of hypoplastic left heart syndrome with intact atrial septum. Am J Obstet Gynecol 2005; 193: 1424-8.

54. Lee W, Comstock CH. Prenatal diagnosis of congenital heart disease: where are we now? Ultrasound Clin 2006; 1: 273-91.

55. Tworetzky W, McElhinney DB, Reddy VM, et al. Improved surgical outcome after fetal diagnosis of hypoplastic left heart syndrome. Circulation 2001; 103: 1269-73.

56. Emery SP, Kreutzer J, Sherman FR, et al. Computer-assisted navigation applied to fetal cardiac intervention. Int J Med Robot 2007; 3: 187-98.

57. Schmidt M, Jaeggi E, Ryan G, et al. Percutaneous ultrasound-guided stenting of the atrial septum in fetal sheep. Ultrasound Obstet Gynecol 2008; 32: 923-8.

58. Turley K, Vlahakes GJ, Harrison MR, et al. Intrauterine cardiothoracic surgery: the fetal lamb model. Ann Thorac Surg 1982; 34: 422-6.

59. Eghtesady P, Sedgwick JA, Schenbeck JL, et al. Maternal-fetal interactions in fetal cardiac surgery. Ann Thorac Surg 2006; 81: 249-55; discussion 255-6.

60. Ikai A, Riemer RK, Ramamoorthy C, et al. Preliminary results of fetal cardiac bypass in nonhuman primates. J Thorac Cardiovasc Surg 2005; 129: 175-81

61. Reddy VM, McElhinney DB, Rajasinghe HA, et al. Role of the endothelium in placental dysfunction after fetal cardiac bypass. J Thorac Cardiovasc Surg 1999; 117: 343-51.

62. Rychik J. Frontiers in fetal cardiovascular disease. Pediatr Clin North Am 2004; 51: 1489-502. 